\title{
A Cross-Sectional Study of Blood Ethylmercury Levels and Cognitive Decline Among Older Adults and the Elderly in the United States
}

\author{
David A. Geier ${ }^{\mathrm{a}, \mathrm{b}}$, Janet K. Kern ${ }^{\mathrm{a}, \mathrm{b}, \mathrm{c}, *}$, Kristin G. Homme ${ }^{\mathrm{d}}$ and Mark R. Geier ${ }^{\mathrm{a}, \mathrm{b}}$ \\ ${ }^{\mathrm{a}}$ Institute of Chronic Illnesses, Inc., Silver Spring, MD, USA \\ ${ }^{\mathrm{b}} \mathrm{CoMeD}$, Inc., Silver Spring, MD, USA \\ ${ }^{\mathrm{c}}$ CONEM US Autism Research Group, Allen, TX, USA \\ ${ }^{\mathrm{d}}$ International Academy of Oral Medicine and Toxicology, ChampionsGate, FL, USA
}

\begin{abstract}
Cognitive health is an emerging public health concern for the aging American population. Mercury $(\mathrm{Hg})$ is a toxic element that can cause nervous system damage. This hypothesis-testing study evaluated the relationship between blood ethyl$\mathrm{Hg}$ levels and cognitive decline in an older adult and elderly American population. A total of 1,821,663 weighted-persons between 60-80 years old with detectable blood ethyl-Hg levels within the 2011-2012 National Health and Nutritional Examination Survey were examined. Those persons with blood ethyl-Hg levels greater than the median were deemed the higher ethyl-Hg exposure group and those with ethyl-Hg levels less than the median were deemed the lower ethyl-Hg exposure group. Three tests were utilized to measure cognitive function: 1) Consortium to Establish a Registry for Alzheimer's Disease - Word List Learning (CERAD W-L) delayed recall test, 2) animal fluency test, and 3) Digit Symbol Substitution Test. Each cognitive test score was categorized as higher for those with scores greater than the median and lower for those with scores less than the median. Survey logistic regression modeling with covariates was used to analyze the data for the relationship between blood ethyl-Hg levels and cognitive function scores. Significantly increased risks for lower animal fluency test (odds ratio $(\mathrm{OR})=13.652, p=0.0029)$ and CERAD W-L delayed recall test $(\mathrm{OR}=6.401, p=0.0433)$ scores were observed among the higher ethyl-Hg exposure group as compared to the lower ethyl-Hg exposure group. This study supports the hypothesis that increased ethyl-Hg exposure is associated with significant cognitive decline in older adult and elderly Americans.
\end{abstract}

Keywords: Ethylmercury, merthiolate, methylmercury, thiomersal

\section{INTRODUCTION}

Cognitive health is an emerging public health concern for the aging population in the United States (US) $[1,2]$. Associated with a decline in cognitive functioning are issues related to quality of life, personal relationships, and independence, and these can

${ }^{*}$ Correspondence to: Janet K. Kern, PhD, MACE, 14 Redgate Ct, Silver Spring, MD 20905, USA. Tel.: +1 214592 6600; Fax: +1 301989 1543; E-mail: jkern@dfwair.net. result in increased healthcare needs, as well as major caregiving and financial challenges [3]. It is estimated that more than 16 million people in the US are currently living with cognitive impairment [4]. Furthermore, an estimated 5.1 million Americans over the age of 65 may currently have Alzheimer's disease, the most well-known form of cognitive impairment, and this number is expected to rise to 13.2 million by 2050 [5]. The average Medicaid nursing facility cost per state in 2010 for persons diagnosed with Alzheimer's disease is estimated at $\$ 647$ million, not 
including home- and community-based care or prescription drug costs [6].

Mercury $(\mathrm{Hg})$ is a toxic element that can cause profound damage to the nervous system as was observed following methyl-Hg poisonings in Japan [7] and Iraq [8] and ethyl-Hg poisonings in Iraq [9] and China [10]. It was previously published that most $\mathrm{Hg}$ exposure in the US today is characterized as occurring from three primary sources: methyl-Hg in fish, $\mathrm{Hg}$ vapor from dental amalgam tooth fillings, and ethyl$\mathrm{Hg}$ in the form of Thimerosal added as a preservative to some vaccines [11]. The potential for low-dose $\mathrm{Hg}$ toxicity in adults is a controversial subject and there is little agreement as to whether a threshold dose exists below which no damage is likely to accrue to the central nervous system [12-14].

The National Health and Nutrition Examination Survey (NHANES) is a major program of the National Center for Health Statistics (NCHS), which is a part of the US Centers for Disease Control and Prevention (CDC). NHANES is designed to assess the health and nutritional status of adults and children in the US by utilizing survey methods that combine interviews, physical examinations, and laboratory tests. It is the aim of NHANES to help determine the prevalence of major diseases and risk factors for diseases, and then, from such data, help to develop sound public health policy.

In light of the importance of cognitive decline and the potential role for $\mathrm{Hg}$ exposures in neurotoxicity, the purpose of the present study was to test the hypothesis that older adults and elderly persons with increasing blood ethyl-Hg levels may have increased measures of cognitive decline, by undertaking a hypothesis testing cross-sectional study of the NHANES database.

\section{METHODS}

The SAS system for Windows, version 9.4 (Cary, NC, USA) was used to examine the NHANES data. This study integrated the 2011-2012 NHANES data from demographic survey questions, cognitive function test results, and laboratory test results. Figure 1 presents a schematic flowchart of the data examined in the present study.

\section{Study participants}

The NHANES is a program of studies designed to assess the health and nutritional status of adults and children in the US. The survey is unique in that it combines interviews with physical and laboratory examinations. NHANES is a major program of the NCHS of the US CDC. The NHANES program began in the early 1960s, and has been conducted as a series of surveys focusing on different population groups or health topics. In 1999, the survey became a continuous program with components that are adaptable to a variety of health and nutritional measurements in order to meet emerging needs. The NHANES examines a nationally representative sample of about 5,000

$261,189,935$ weighted-persons

(All Ages)

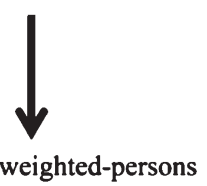

$39,003,118$ weighted-persons

(60 to 80 years-old and underwent cognitive testing)

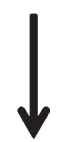

$1,821,663$ weighted-persons

(only persons with blood ethylmercury levels above detection limits)

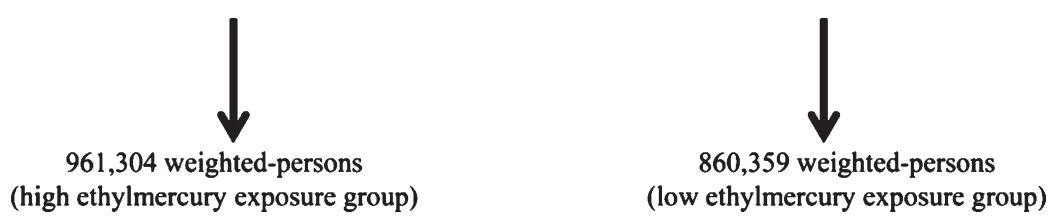

Fig. 1. A schematic flowchart of the data examined in the present study. 
Americans each year, and these persons are located in counties across the US, 15 of which are visited each year.

The 2011-2012 NHANES data collection methods were approved by the NCHS Research Ethics Review Board (ERB) (Protocol\#2011-17). According to the NHANES, the interviewers first determine if someone is eligible to participate. The NHANES interviewer goes to the home and asks the potential participant questions to see if the person will qualify to participate. Each study subject provided informed consent to participate in the NHANES program. The NHANES consent process was also overseen by the NCHS-ERB. The health information collected in the NHANES program is kept in strictest confidence and is only used for stated purposes.

An overall population of $39,003,118$ weightedpersons between the ages of 60 and 80 years with non-missing values for the demographic, cognitive function, and laboratory test result variables were examined in this study. The number of weighted-persons was derived by applying the full sample two-year mobile examination weight variable (WTMEC2YR) to each person examined in this study. The WTMEC2YR variable was created by the NHANES program. The WTMEC2YR is a measure of the number of persons in the general population that a sampled individual represents and is needed to obtain unbiased estimates of population parameters when sample participants are chosen with unequal probabilities. The demographic variables for the population were identified from within the NHANES demographic dataset. The variables examined were as follows: gender, age in years at examination, race (non-Hispanic White, nonHispanic Black, non-Hispanic Asian, Hispanic, or other), and socioeconomic status (poverty income ratio (PIR) - a ratio of family income to poverty threshold). The PIR variable was created by the NHANES program.

\section{Exposures}

The blood $\mathrm{Hg}$ exposure variables were identified from within the NHANES mercury blood dataset. These included: inorganic Hg, ethyl-Hg, and methyl$\mathrm{Hg}$. Blood samples were eligible for collection on all persons 1-year-old and older who were medically examined by the NHANES project. The blood samples included as part of the NHANES dataset were processed, stored, and shipped to the CDC's Division of Laboratory Sciences, National Center for Environ- mental Health for analysis. The blood $\mathrm{Hg}$ compounds were measured by analyzing blood through the use of Solid Phase Micro Extraction (SPME) fiber for delivering sample to gas chromatography (GC) coupled to inductively coupled plasma-dynamic reaction cell-mass spectrometry (ICP-DRC-MS). The method employed provided an accurate measure of the quantity of inorganic $\mathrm{Hg}$, methyl- $\mathrm{Hg}$, and ethyl-Hg present in the blood samples examined [15]. Since the primary focus of the present study was to examine the potential consequences of blood ethyl-Hg exposure, it was required that all persons examined in this study had blood ethyl-Hg levels at or above the detection limit. All persons with blood ethyl-Hg levels below the lower detection limit were excluded. The blood ethyl-Hg data were then analyzed using the survey means procedure in SAS to determine the median blood ethyl-Hg level for the persons examined $($ median $=0.195 \mu \mathrm{g}$ ethyl-Hg/L). Those persons with blood ethyl-Hg levels greater than the median were deemed the higher ethyl-Hg exposure group (961,304 weighted-persons) and those persons with blood ethyl-Hg levels less than the median were deemed the lower ethyl-Hg exposure group $(860,359$ weighted-persons).

\section{Outcomes}

The cognitive function NHANES dataset was examined for the cognitive function status of persons examined in this study. Cognitive function status was assessed on eligible persons 60 years old and older who were medically examined by the NHANES project. The assessments were administered by trained interviewers at the end of the face-to-face interview in the Mobile Examination Center. The Consortium to Establish a Registry for Alzheimer's Disease Word List Learning (CERAD W-L) [16] test for delayed recall, animal fluency test, and Digit Symbol Substitution Test (DSST) were utilized to measure cognitive functioning status in this study. These are well-established, validated measures. The data for each cognitive test were analyzed using the survey means procedure in SAS and revealed the following median values: CERAD W-L for delayed recall $=6.12$, animal fluency test $=19.480$, and DSST $=60.41$. Analyzing each cognitive test separately for cognitive performance, persons were rated to have higher cognitive performance on any test if their test score was greater than the median test score and lower cognitive performance on any test if their test score was less than the median test score. 


\section{Statistical analyses}

In all statistical analyses, the statistical package in SAS was utilized, and a two-sided $p$-value $<0.05$ was considered statistically significant. The null hypothesis was that there would be no relationship between blood ethyl-Hg levels and cognitive function test scores. The data were examined using the survey logistic regression modeling procedure in SAS. The model evaluated the relationship between increasing blood ethyl-Hg levels and the risk of lower performance for each of the cognitive tests examined. The model also includes the covariates of blood inorganic $\mathrm{Hg}$ levels, blood methyl-Hg levels, gender, age in years at examination, race, and socioeconomic status. The number of persons examined in this study was sufficient to allow for adequate statistical power for the analyses undertaken in this study.

\section{RESULTS}

Table 1 displays the demographic characteristics of the population of persons examined in the NHANES database. It was observed that the higher ethyl-Hg exposure group in comparison to the lower ethyl-
$\mathrm{Hg}$ exposure group had similar overall mean ages of about 66 years old. The female to male ratio ( 2.2 versus 0.82 ) and the percentage of non-Hispanic Whites ( $81 \%$ versus $74 \%$ ) were increased in the higher ethyl-Hg exposure group in comparison to the lower ethyl-Hg exposure group. By contrast, the mean PIR score was lower in the high ethyl-Hg exposure group (2.4) in comparison to the lower ethyl- $\mathrm{Hg}$ exposure group (2.9). In other words, the higher ethyl-Hg group was disproportionately female, white, and less affluent. It was also observed that mean blood methyl$\mathrm{Hg}(5.5 \mu \mathrm{g}$ methyl-Hg/L versus $2.2 \mu \mathrm{g}$ methyl- $\mathrm{Hg} / \mathrm{L})$ and inorganic $\mathrm{Hg}(0.4 \mu \mathrm{g} \mathrm{Hg} / \mathrm{L}$ versus $0.3 \mu \mathrm{g} \mathrm{Hg} / \mathrm{L})$ levels were greater in the higher ethyl-Hg exposure group in comparison to the lower ethyl-Hg exposure group.

Table 2 displays the results of the survey logistic regression models examined to determine the impact of blood ethyl-Hg exposure on tests measuring cognitive decline. It was observed that those persons having lower animal fluency scores (odds ratio $=13.652$, $p=0.0029)$ or lower CERAD W-L delayed recall scores (odds ratio $=6.401, p=0.0433$ ) were significantly more likely to have higher ethyl-Hg exposure as compared to lower ethyl-Hg exposure. It was

Table 1

Demographic characteristics of persons examined in the NHANES database

\begin{tabular}{|c|c|c|c|}
\hline Parameter Examined & $\begin{array}{c}\text { Overall Ethylmercury } \\
\text { Exposure Group } \\
(1,821,663 \text { weighted-persons })\end{array}$ & $\begin{array}{c}\text { Higher Ethylmercury } \\
\text { Exposure Group }{ }^{1} \\
\text { (961,304 weighted-persons) }\end{array}$ & $\begin{array}{c}\text { Lower Ethylmercury } \\
\text { Exposure Group }{ }^{2} \\
\text { (860,359 weighted persons) }\end{array}$ \\
\hline \multicolumn{4}{|l|}{ Age } \\
\hline Mean Age \pm std (age range: $60-80$ ) & $66.5 \pm 5.2$ & $66.6 \pm 5.0$ & $66.3 \pm 5.5$ \\
\hline \multicolumn{4}{|l|}{ Gender $(\%)$} \\
\hline Male & $770,588(42 \%)$ & $297,688(31 \%)$ & $472,900(55 \%)$ \\
\hline Female & $1,051,075(58 \%)$ & $663,616(69 \%)$ & $387,459(45 \%)$ \\
\hline \multicolumn{4}{|l|}{ Race $(\%)$} \\
\hline Non-Hispanic White & $1,410,378(77 \%)$ & $777,922(81 \%)$ & $632,457(73 \%)$ \\
\hline Non-Hispanic Black & $35,546(2 \%)$ & $35,546(4 \%)$ & $0(0 \%)$ \\
\hline Non-Hispanic Asian & $86,818(5 \%)$ & $86,818(9 \%)$ & $0(0 \%)$ \\
\hline Hispanic & $101,343(6 \%)$ & $61,018(6 \%)$ & $40,325(5 \%)$ \\
\hline Other $^{3}$ & $187,578(10 \%)$ & $0(0 \%)$ & $187,578(22 \%)$ \\
\hline \multicolumn{4}{|l|}{ Socioeconomic Status (score range: $0-5$ ) } \\
\hline Mean PIR Score \pm std & $2.6 \pm 1.6$ & $2.4 \pm 1.6$ & $2.9 \pm 1.4$ \\
\hline \multicolumn{4}{|l|}{ Blood Mercury Levels ( $\mu \mathrm{g} / \mathrm{L})$} \\
\hline Mean Ethylmercury \pm std (range) & $0.3 \pm 0.2(0.16-1.0)$ & $0.38 \pm 0.25(0.20-1.00)$ & $0.17 \pm 0.01(0.16-0.19)$ \\
\hline Mean Methylmercury \pm std (range) & $4.0 \pm 5.3(0.08-23.2)$ & $5.5 \pm 6.4(0.2-23.2)$ & $2.2 \pm 3.0(0.1-8.7)$ \\
\hline Mean Inorganic mercury \pm std (range) & $0.4 \pm 0.3(0.2-2.8)$ & $0.4 \pm 0.4(0.2-2.8)$ & $0.3 \pm 0.1(0.2-0.5)$ \\
\hline \multicolumn{4}{|l|}{ Cognitive Test Scores } \\
\hline Mean Animal Fluency Score \pm std (range) & $18.7 \pm 4.9(3-28)$ & $17.4 \pm 4.0(10-24)$ & $20.2 \pm 5.3(3-28)$ \\
\hline $\begin{array}{l}\text { Mean CERAD W-L Delayed } \\
\text { Recall Score } \pm \text { std (range) }\end{array}$ & $6.7 \pm 1.7(2-10)$ & $6.4 \pm 1.7(2-10)$ & $7.0 \pm 1.6(5-9)$ \\
\hline Mean Digit Symbol Score \pm std (range) & $56.6 \pm 11.6(13-79)$ & $56.9 \pm 10.6(13-79)$ & $56.3 \pm 12.5(23-73)$ \\
\hline
\end{tabular}

PIR, poverty income ratio; std, standard deviation of the mean. ${ }^{1}$ Those persons with blood ethyl-Hg levels greater than the median of $0.195 \mu \mathrm{g}$ ethyl-Hg/L were considered the higher ethyl-Hg exposure group. ${ }^{2}$ Those persons with blood ethyl-Hg levels less than the median of $0.195 \mu \mathrm{g}$ ethyl-Hg/L were considered the lower ethyl-Hg exposure group. ${ }^{3}$ Includes persons of Asian, mixed race, or other ancestry. 
Table 2

Survey logistic regression models ${ }^{1}$ examining the impact of blood ethylmercury levels on tests measuring cognitive decline in the NHANES database

\begin{tabular}{|c|c|c|c|c|}
\hline Cognitive Decline Testing Type & Variables & Odds Ratio & 95\% Confidence Interval & $p$ \\
\hline \multirow{7}{*}{ Lower Digit Symbol Scores } & Blood Ethylmercury (Higher versus Lower) & 2.919 & 0.191 to 44.699 & 0.4415 \\
\hline & Blood Methylmercury (Higher versus Lower) & 0.940 & 0.657 to 1.346 & 0.7368 \\
\hline & Blood Inorganic Mercury (Higher versus Lower) & 0.180 & 0 to 41.608 & 0.5370 \\
\hline & Gender (Female versus Male) & 0.632 & 0.038 to 10.544 & 0.7494 \\
\hline & Race & 0.914 & 0.497 to 1.678 & 0.7706 \\
\hline & Age & 0.993 & 0.710 to 1.388 & 0.9659 \\
\hline & Socioeconomic Status & 0.344 & 0.187 to 0.633 & 0.0006 \\
\hline \multirow[t]{7}{*}{ Lower Animal Fluency Scores } & Blood Ethylmercury (Higher versus Lower) & 13.652 & 2.444 to 76.252 & 0.0029 \\
\hline & Blood Methylmercury (Higher versus Lower) & 0.935 & 0.799 to 1.094 & 0.4023 \\
\hline & Blood Inorganic Mercury (Higher versus Lower) & 0.074 & 0 to 38.639 & 0.4147 \\
\hline & Gender (Female versus Male) & 0.129 & 0.023 to 0.724 & 0.0200 \\
\hline & Race & 1.042 & 0.739 to 1.469 & 0.8157 \\
\hline & Age & 1.178 & 1.111 to 1.249 & $<0.0001$ \\
\hline & Socioeconomic Status & 0.766 & 0.412 to 1.423 & 0.3989 \\
\hline Lower CERAD Word & Blood Ethylmercury (Higher versus Lower) & 6.401 & 1.057 to 38.754 & 0.0433 \\
\hline Learning subtest & Blood Methylmercury (Higher versus Lower) & 0.737 & 0.606 to 0.897 & 0.0023 \\
\hline Delayed Recall & Blood Inorganic Mercury (Higher versus Lower) & 0.899 & 0.285 to 2.839 & 0.8559 \\
\hline \multirow[t]{4}{*}{ Scores } & Gender (Female versus Male) & 0.030 & 0.005 to 0.189 & 0.0002 \\
\hline & Race & 1.635 & 0.874 to 3.061 & 0.1240 \\
\hline & Age & 2.198 & 1.700 to 2.841 & 0.2754 \\
\hline & Socioeconomic Status & 2.198 & 1.700 to 2.841 & $<0.0001$ \\
\hline
\end{tabular}

${ }^{1}$ The survey logistic models employed used stratum, cluster, and weight. They were adjusted for blood methylmercury levels, blood inorganic mercury levels, age, gender, race, and socioeconomic status. Bold-Italicized results are statistically significant.

also observed that lower animal fluency scores (odds ratio $=0.129, p=0.0200$ ) or lower CERAD W-L delayed recall scores (odds ratio $=0.030, p=0.0002$ ) were significantly less common among females as compared to males. In addition, lower animal fluency scores (odds ratio $=1.178, p<0.0001$ ) were significantly associated with increasing age, and lower CERAD W-L delayed recall scores (odds ratio $=0.737, p=0.0023$ ) were significantly reduced by increasing blood methyl-Hg levels. By contrast, lower digit symbol scores were not significantly associated with increasing ethyl-Hg exposure.

\section{DISCUSSION}

The present hypothesis-testing study is the first epidemiological study to evaluate the potential relationship between increasing exposure to ethyl-Hg and cognitive decline in older adults and elderly Americans. It was observed in statistical modeling with covariates among older adults and elderly persons that increasing blood ethyl-Hg levels were significantly associated with measures of increasing cognitive decline.

In considering the source of exposure for the blood ethyl-Hg observed in the present study, one of the possible sources of ethyl-Hg was Thimerosal-containing seasonal influenza vaccines. As described previously, an estimated $44 \%$ of persons 50 to 64 years old and $70 \%$ of persons 65 years old and older in the US during the 2011 to 2012 time period received seasonal influenza vaccine [17] and most of seasonal influenza vaccines administered to this population were in multi-dose vial preparations that utilized Thimerosal as a preservative to prevent bacterial/fungal contamination [18]. Unfortunately, the data in NHANES does not provide detailed vaccination histories that would be relevant to our current analyses. It is also important consider that mercury-free vaccine formulations are available, and vaccines are an important health tool to reduce the morbidity and mortality associated with infectious diseases.

The tests utilized to measure cognitive decline in the present study may provide an important insight into the type of impact ethyl-Hg has on the aging brain. The NHANES used the CERAD W-L delayed recall test to assess both immediate and delayed learning ability for new verbal information [19]. The test involved three consecutive learning trials and one delayed recall trial. For the learning trials, 10 unrelated words are presented in large bolded letters on a computer monitor and read out loud by the study participant. Then, the study participants were asked to recall as many words as possible for a maximum score of 10 . The order of the words is changed in each of the three consecutive learning trials. If the 
study participant cannot read, the interviewer reads the words out loud. In the NHANES, the delayed word recall test was given after the DSST and animal fluency test were completed, which is about $8-10$ minutes from the beginning of the consecutive learning trials. The CERAD W-L delayed recall test has been used successfully in several epidemiologic studies [20-23].

The NHANES used the animal fluency test to determine categorical verbal fluency. In verbal fluency tests participants are asked to say as many words as possible from a category in a short period of time [24]. In this venue, participants are asked to name as many animals as possible in one minute. Verbal fluency test scores can be used differentiate between persons with normal cognition and those with cognitive impairment, ranging from mild to severe [25-27]. The animal fluency test has been used successfully in several epidemiologic studies [26-28].

The performance module from the Wechsler Adult Intelligence Scale (WAIS III), the DSST, requires sustained attention, adequate processing speeds, and working memory [29]. In this test participants are shown a key containing nine numbers that are paired with symbols and then the participant has two minutes to copy the corresponding symbols in the 133 boxes that adjoin the numbers. The DSST is a sensitive measure in regard to brain damage and dementia and has been used successfully in several epidemiological and clinical studies [30-32].

It is useful to consider the plausibility of this study from a neuroscience perspective. The NHANES used three measures to examine cognitive functioning, and all three were examined and described in this current study. Two of the measures (CERAD W-L delayed recall test and animal fluency test) showed effects from ethyl-Hg exposure, and one measure (DSST) did not show effects from ethyl-Hg exposure. These results can be explained by understanding $\mathrm{Hg}$ effects on the brain. The two measures that showed effects involve memory recall. Several studies report that $\mathrm{Hg}$ exposure has a detrimental impact on memory recall. This phenomenon is found in children, adults of various ages, and the elderly [33-37]. Memory recall requires reconstruction of elements scattered in disparate parts of the brain to be linked together by associations and neural networks [38, 39]; in other words, it requires global processing. $\mathrm{Hg}$ is known to destroy long-range connections in the brain, the connections that bring disparate parts of the brain together [40], and such phenomena was previously observed among infants receiving increased ethyl-
$\mathrm{Hg}$ exposure [41]. On the other hand, the third test, the DSST, did not show effects from $\mathrm{Hg}$ exposure. The exact reason for this observation is not clear. The DSST comprises a range of cognitive functions, including processing speed, attention, and executive function [29]. However, the DSST test requires matching of the numbers 1 to 9 with various symbols and numbers and symbols are both processed in the same area of the brain, the inferior temporal cortex $[42,43]$. The fact that numbers and symbols are processed in the same area of the brain suggests that the DSST test may require less of a demand on long range axons. When $\mathrm{Hg}$ destroys neuronal axons, shorter axons (the ones involved in localized processing) can be replaced; however, long-range axons involved on global processing cannot be replaced. Hence, localized processing may remain intact, showing normal test results even after $\mathrm{Hg}$ exposure, whereas global processing is often notably affected [40].

The results of this study showing a significant relationship between increasing blood ethyl-Hg levels and cognitive decline in the older adults and elderly are biologically plausible. Thimerosal is the virtually only source of human exposure to ethyl-Hg. Thimerosal is an ethyl-Hg containing compound that is $49.55 \% \mathrm{Hg}$ by weight that rapidly dissociates into ethyl-Hg chloride and ethyl-Hg hydroxide in aqueous solutions and biological systems [44]. It was observed following administration of Thimerosalcontaining vaccines to humans that blood $\mathrm{Hg}$ levels were increased within the first few weeks following exposure [45]. In addition, it was described that ethyl- $\mathrm{Hg}$ is actively transported into human neuronal cells by the L-type neutral amino acid carrier transport (LAT) system [46], and human topical application of Thimerosal significantly increased brain $\mathrm{Hg}$ levels [47]. It was observed in animal studies that during the acute phase of ethyl-Hg exposure from Thimerosal-containing vaccines that the brainto-blood partitioning ratio of $\mathrm{Hg}$ was $3.5: 1$. By contrast, over a significantly longer period following ethyl-Hg exposure from Thimerosal-containing vaccines, blood $\mathrm{Hg}$ levels approached zero while significant levels of $\mathrm{Hg}$ still persisted in the brain [48].

The present study only examined persons with detectable levels of blood ethyl-Hg. As a result, it was assumed that such persons were in the acute phase of ethyl-Hg exposure from Thimerosal-containing vaccines, and, as such, helped to ensure a similar type of exposure pattern among all those persons examined. Among those persons with undetectable levels 
of blood ethyl-Hg, they may have not been exposed or had previously been exposed over a significantly longer period in the past to Thimerosal-containing vaccines. This type of unpredictability in past exposure, coupled with lack of a blood biomarker for past ethyl-Hg exposure, resulted in such persons being excluded from analyses undertaken in this study.

It is also important to consider the results observed in this study with previous epidemiological studies evaluating various sources of $\mathrm{Hg}$ exposure and cognitive function in older adults and elderly Americans. For example, the first epidemiological study to evaluate the relationship between $\mathrm{Hg}$ exposure and cognitive function in elderly Americans was a crosssectional epidemiological study undertaken on 474 randomly selected persons in the Baltimore Memory Study [49]. These investigators observed, after adjustment for covariates, that increasing blood $\mathrm{Hg}$ levels were associated with worse performance on the Rey complex figure delayed recall test (a test of visual memory). However, these investigators also observed that increasing blood $\mathrm{Hg}$ levels were associated with better performance on finger tapping (a test of manual dexterity). These investigators concluded that their data do not provide strong evidence that blood $\mathrm{Hg}$ levels significantly impact neurobehavioral performance in elderly adults.

As an additional example, a cross-sectional epidemiological study was undertaken on 384 elderly Americans at the Carillon Outpatient Center in St. Petersburg, Florida [12]. These investigators observed that the relationship between $\mathrm{Hg}$ exposure and cognitive performance revealed that when compared to persons with moderate blood $\mathrm{Hg}$ levels, those with high and low blood $\mathrm{Hg}$ levels performed significantly worse in complex-information processing testing. These investigators further evaluated their data and determined that the mediating factor for the relationships observed was the amount of omega-3 fatty acids. Since the main source for blood $\mathrm{Hg}$ in the persons examined was fish, and fish contain significant amounts of omega- 3 fatty acids, the investigators reported that when compared to those persons with low blood $\mathrm{Hg}$ levels and corresponding lower levels of omega-3 fatty acid exposure (e.g., persons eating very little fish) to those with moderate blood $\mathrm{Hg}$ levels and corresponding increased levels of omega-3 fatty acid exposure (e.g., persons eating moderate amounts of fish), the benefits of the omega-3 fatty acid exposure significantly outweighed the negative effects of the concomitant $\mathrm{Hg}$ exposure on complexinformation processing test scores. Whereas at high blood $\mathrm{Hg}$ levels (e.g., persons eating large amounts of fish) as compared to those with moderate blood $\mathrm{Hg}$ levels, the negative impacts of high blood $\mathrm{Hg}$ levels overwhelmed the beneficial effects of omega-3 fatty acid exposure, and hence, such persons manifested with significantly worse complex-information processing test scores. The researchers commented that the likely difference between their findings and those in the Baltimore Memory Study was the consequence of blood $\mathrm{Hg}$ levels being so significantly lower in the Baltimore Memory Study.

The results observed in the aforementioned studies are consistent with those observed in the present study, but the present study is differentiated from them. Specifically, the present study examined blood samples that underwent $\mathrm{Hg}$ speciation testing to determine the amounts of ethyl- $\mathrm{Hg}$, methyl- $\mathrm{Hg}$, and inorganic $\mathrm{Hg}$ in the blood. By contrast, the aforementioned studies examined total blood $\mathrm{Hg}$ levels. Therefore, each of the $\mathrm{Hg}$ speciation variables examined were entered into the models constructed to allow for a more accurate determination of their relative impact on cognitive function. Further, unlike the previous studies where the primary source of $\mathrm{Hg}$ exposure was from fish (in the form of methyl- $\mathrm{Hg}$ ), the primary focus of this study was on blood ethyl-Hg levels, which Thimerosal added as a preservative to some vaccines was one possible source. As a result, blood ethyl-Hg exposures were not confounded by the beneficial effects of $n-3$ fatty acid exposure associated with blood methyl-Hg exposures, and the present study actually examined blood methyl-Hg and inorganic $\mathrm{Hg}$ levels as covariates.

Overall, it was observed in the present study that mean blood methyl-Hg $(5.5 \mu \mathrm{g}$ methyl-Hg/L versus $2.2 \mu \mathrm{g}$ methyl- $\mathrm{Hg} / \mathrm{L})$ and inorganic $\mathrm{Hg}(0.4 \mu \mathrm{g}$ $\mathrm{Hg} / \mathrm{L}$ versus $0.3 \mu \mathrm{g} \mathrm{Hg} / \mathrm{L}$ ) levels were greater in the high ethyl-Hg exposure group in comparison to the low ethyl-Hg exposure group. However, it was observed that greater methyl-Hg levels were significantly associated with improved cognitive function. As described previously, since the primary source of methyl-Hg is fish, which contains beneficial omega3 fatty acids, this result is most likely related to the beneficial effects of fish and omega-3 fatty acid levels [50]. The results observed for blood inorganic $\mathrm{Hg}$ showed no significant relationship with cognitive function. It is not known why blood inorganic $\mathrm{Hg}$ showed no significant relationship with cognitive function in the population examined in this study. It is recommended in future NHANES studies that further examinations be undertaken to evaluate the 
relationship between blood $\mathrm{Hg}$ levels and cognitive function.

\section{Study limitations}

As with any observational cross-sectional study, it was not possible to follow the participants examined on a longitudinal basis to evaluate the relationship between exposures and outcomes. Despite this limitation, the blood ethyl- $\mathrm{Hg}$ and cognitive function tests were completed on a contemporaneous basis. In addition, the results observed in this study, as described previously, are biologically plausible and are supported by previous epidemiological studies showing blood $\mathrm{Hg}$ levels were associated with cognitive decline in elderly persons. The present study was also not able to determine if the measures of cognitive decline were transient or persistent. It is recommended that future studies further explore the phenomenon observed in this study within other populations examined on a prospective longitudinal cohort basis.

The NHANES program uses the questionnaire method of data collection and participants may recall information wrongly or reported information inaccurately. However, the demographic, socioeconomic, dietary, and health-related questions are detailed and consistent and asked during an interview with highly trained study personnel. In addition, for the data examined, it is presumed that such limitations or errors in the data would have applied equally to all participants examined. Conceivably, such errors in the data would have most likely reduced the statistical power of this study to be able to reveal significant relationships.

It is also a potential limitation of this study that cognitive decline was assessed using only three wellestablished measures of cognitive function. It is possible that some persons had other symptoms of cognitive decline or their symptoms were so mild that they were not detected using the testing employed in this study. Despite this fact, significant adverse effects of increasing blood ethyl-Hg on cognitive function were observed in two of the three cognitive tests employed in this study. It is recommended that future studies employ other tests and measurements of cognitive decline to more fully evaluate ethyl- $\mathrm{Hg}$ associated effects on cognitive function.

A further potential limitation of this study was that persons with less than detectable blood ethyl-Hg levels were excluded. These persons were excluded, because as discussed previously, the most likely source of ethyl-Hg exposure was from Thimerosalcontaining influenza vaccine administration, and there are social and medical attributes that may be associated with both avoidance or delay of vaccination; and confounding of this sort is a general problem for studies of prophylactic interventions [51]. In the context of influenza vaccination of older adults and the elderly, this type of phenomena may have been observed when it was reported that the risk of death from all causes was about 50\% lower in persons receiving influenza vaccination as compared to persons not receiving influenza vaccination [52]. This type of phenomena may also have been observed in the data examined in this study. For example, when examining persons with blood ethyl-Hg levels at or above the detection limit in comparison to those persons with blood ethyl-Hg levels below detection limits in relation to animal fluency test scores, the risk of lower animal fluency test scores were significantly reduced by blood ethyl-Hg levels at or above the detection limit (odds ratio $=0.379, p=0.0250$ ). Hence, by requiring that all persons examined in this study to have detectable levels of blood ethyl-Hg, it means that everyone was most likely exposed to Thimerosal-containing influenza vaccine and potential sources of confounding associated with avoidance or delay of vaccination were minimized. However, the exact source of the ethyl-Hg cannot be determined from the NHANES data.

A potential limitation of this study was that no calculation and justification of the sample size was conducted. Despite this potential limitation, several statistically significant results were observed in this study.

It is possible that the results observed could have been the result of chance and that would have to be considered as a potential limitation of the study; however, that would be unlikely since only a small number of statistical tests were conducted and the direction and magnitude of the results were biologically plausible. In addition, the data were analyzed using median values to establish higher versus lower ethyl-Hg exposure cut-offs and lower versus higher cognitive performance cut-offs to minimize any potential outlier effects on the results observed, especially since a relatively small sample size of persons were examined in the current study.

Finally, while the present study observed a significant association between increasing blood ethyl-Hg levels with cognitive decline in older adults and the elderly, the present study did not examine the potential impact of other environmental risk fac- 
tors for cognitive decline well-described in previous systematic reviews. It was reported that there is at least moderate evidence implicating air pollution, aluminum, silicon, selenium, pesticides, vitamin $\mathrm{D}$ deficiency, and electric and magnetic fields in the etiology of cognitive decline [53]. It would be worthwhile in future studies to further examine how various different environmental exposures may work independently or synergistically to induce cognitive decline.

\section{Conclusion}

This cross-sectional study provides the first epidemiological evidence linking increasing blood ethyl-Hg levels with cognitive decline in older adults and elderly Americans. It is recommended that future longitudinal cohort studies be conducted for consistency with the observations made in the present study and to determine the persistence of cognitive decline symptoms associated with ethyl-Hg exposure in older adults and the elderly.

\section{ACKNOWLEDGMENTS}

This research was funded by the non-profit organizations, CoMeD, Inc. and Institute of Chronic Illnesses, Inc.

Authors' disclosures available online (https:// www.j-alz.com/manuscript-disclosures/19-0894r1).

\section{REFERENCES}

[1] Alzheimer's Association and Centers for Disease Control and Prevention (2013) The Healthy Brain Initiative: The Public Health Road Map for State and National Partnerships, 2013-2018. Alzheimer's Association, Chicago, IL.

[2] Centers for Disease Control and Prevention (2015) The Healthy Brain Initiative: The Public Health Road Map for State and National Partnerships, 2013-2018, Interim Progress Report. CDC, Atlanta, GA. Available from: https://www.cdc.gov/aging/pdf/2013-healthy-braininitiative-interim-report.pdf. Accessed 27 May 2018.

[3] Anderson LA, McConnell SR (2007) Cognitive health: an emerging public health issue. Alzheimers Dement 3, S70S73.

[4] U.S. Department of Health and Human Services, Centers for Disease Control and Prevention. Cognitive impairment: A Call for Action, Now! https://www.cdc.gov/aging/pdf/ cognitive_impairment/cogimp_poilicy_final.pdf. Posted February 2011. Accessed on 15 April 2018.

[5] Herbert LE, Scherr PA, Bienias JL, Bennett DA, Evans DA (2003) Alzheimer's disease in the U.S. population: Prevalence estimates using the 2000 census. Arch Neurol 60, 1119-1122.
[6] Alzheimer's Association (2001) Medicare and Medicaid costs for people with Alzheimer's disease. Alzheimer's Association, Chicago.

[7] Kurland LT, Faro SN, Siedler H (1960) Minamata disease. The outbreak of a neurologic disorder in Minamata, Japan, and its relationship to the ingestion of seafood contaminated by mercuric compounds. World Neurol 1, 370-395.

[8] Bakir F, Damluji SF, Amin-Zaki L, Murtadha M, Khalidi A, al-Rawi NY, Tikriti S, Dahahir HI, Clarkson TW, Smith JC, Doherty RA (1973) Methylmercury poisoning in Iraq. Science 181, 230-241.

[9] Jalili MA, Abbasi AH (1961) Poisoning by ethyl mercury toluene sulphonanilide. Br J Ind Med 18, 303-308.

[10] Zhang J (1984) Clinical observations in ethyl mercury chloride poisoning. Am J Ind Med 5, 251-258.

[11] Clarkson TW (2002) The three modern faces of mercury. Environ Health Perspect 110(Suppl 1), 11-23.

[12] Masley SC, Masley LV, Gualtieri T (2012) Effect of mercury levels and seafood intake on cognitive function in middleaged adults. Integr Med 11, 32-40.

[13] Mozaffarian D, Rimm EB (2006) Fish intake, contaminants, and human health: evaluating the risks and the benefits. JAMA 296, 1885-1899.

[14] WHO (2005) Mercury in health care; policy paper. World Health Organization, Geneva.

[15] Rahman GM, Wolle MM, Fahrenholz T, Kingston HM, Pamuku M (2014) Measurement of mercury species in whole blood using speciated isotope dilution methodology integrated with microwave-enhanced solubilization and spike equilibration, headspace-solid-phase microextraction, and GC-ICP-MS analysis. Anal Chem 86, 6130-6137.

[16] van BG, Fillenbaum G, Mellits ED, Clark C (1989) The consortium to establish a registry for Alzheimer's Disease (CERAD). Part I. Clinical and neuropsychological assessment of Alzheimer's disease. Neurology 39, 1159-1165.

[17] Lu PJ, Singleton JA, Euler GL, Williams WW, Bridges CB (2013) Seasonal influenza vaccination coverage among adult populations in the United States, 2005-2011. Am J Epidemiol 178, 1478-1487.

[18] Geier DA, King PG, Hooker BS, Dorea JG, Kern JK, Geier MR (2015) Thimerosal: clinical, epidemiologic, and biochemical studies. Clin Chim Acta 444, 212-220.

[19] Morris JC, Heyman A, Mohs RC, Hughes JP, van Belle G, Fillenbaum G, Mellits ED, Clark C (1989) The Consortium to Establish a Registry for Alzheimer's disease (CERAD). Part 1. Clinical and neuropsychological assessment of Alzheimer's disease. Neurology 39, 1159-1165.

[20] Fillenbaum GG, van Belle G, Morris JC, Mohs RC, Mirra SS, Davis PC, Tariot PN, Silverman JM, Clark CM, WelshBohmer KA, Heyman A (2008) Consortium to Establish a Registry for Alzheimer's Disease (CERAD): The first twenty years. Alzheimers Dement 4, 96-109

[21] Gao S, Jin Y, Unverzagt FW, Liang C, Hall KS, Ma F, Murrell JR, Cheng Y, Matesan J, Bian J, Li P, Hendrie HC (2009) Hypertension and cognitive decline in rural elderly Chinese. $J$ Am Geriatr Soc 57, 1051-1057.

[22] Lee DY, Lee KU, Lee JH, Kim KW, Jhoo JH, Kim SY, Yoon JC, Woo SI, Ha J, Woo JI (2004) A normative study of the CERAD neuropsychological assessment battery in the Korean elderly. J Int Neuropsychol Soc 10, 72-81.

[23] Prince M, Acosta D, Chiu H, Scazufca M, Varghese M; 10/66 Dementia Research Group (2003) Dementia diagnosis in developing countries: a cross-cultural validation study. Lancet 361, 909-917. 
[24] Strauss E, Sherman EMS, Spreen O (2006) A Compendium of Neuropsychological Tests: Administration, Norms and Commentary (3rd edition). Oxford University Press, New York.

[25] Henry JP, Crawford JR, Phillips LH (2004) Verbal fluency performance in dementia of the Alzheimer's type: a metaanalysis. Neuropsychologia 42, 1212-1222.

[26] Clark LJ, Gatz M, Zheng L, Chen YL, McCleary C, Mack WJ (2009) Longitudinal verbal fluency in normal aging, preclinical and prevalent Alzheimer's disease. Am J Alzheimers Dis Other Dement 24, 461-468.

[27] Duff Canning SJ, Leach L, Stuss D, Ngo L, Black SE (2004) Diagnostic utility of abbreviated fluency measures in Alzheimer disease and vascular dementia. Neurology $\mathbf{6 2}$, 556-562.

[28] Grundman M, Petersen RC, Ferris SH, Thomas RG, Aisen PS, Bennett DA, Foster NL, Jack CR Jr, Galasko DR, Doody R, Kaye J, Sano M, Mohs R, Gauthier S, Kim HT, Jin S, Schultz AN, Schafer K, Mulnard R, van Dyck CH, Mintzer J, Zamrini EY, Cahn-Weiner D, Thal LJ; Alzheimer's Disease Cooperative Study (2004) Mild cognitive impairment can be distinguished from Alzheimer disease and normal aging for clinical trials. Arch Neurol 61, 59-66.

[29] Wechsler D (1997) WAIS Manual - Third Edition. Psychological Corporation, New York.

[30] Bienias JL, Beckett LA, Bennett DA, Wilson RS, Evans DA (2003) Design of the Chicago Health and Aging Project (CHAP). J Alzheimers Dis 5, 349-355.

[31] Plassman BL, Langa KM, Fisher GG, Heeringa SG, Weir DR, Ofstedal MB, Burke JR, Hurd MD, Potter GG, Rodgers WL, Steffens DC, Willis RJ, Wallace RB (2007) Prevalence of dementia in the United States, the Aging, Demographics, and Memory Study. Neuroepidemiology 29, 125-132.

[32] Proust-Lima C, Amieva H, Dartigues J, Jacqmin-Gadda H (2007) Sensitivity of four psychometric tests to measure cognitive changes in brain aging-population-based studies. Am J Epidemiol 165, 344-350.

[33] Zachi EC, Ventura DF, Faria MA, Taub A (2007) Neuropsychological dysfunction related to earlier occupational exposure to mercury vapor. Braz J Med Biol Res 40, 425433.

[34] Zachi EC, Taub A, Faria MAM, Ventura DF (2008) Neuropsychological alterations in mercury intoxication persist several years after exposure. Dement Neuropsychol 2, 91-95.

[35] Lam HS, Kwok KM, Chan PH, So HK, Li AM, Ng PC, Fok TF (2013) Long term neurocognitive impact of low dose prenatal methylmercury exposure in Hong Kong. Environ Int 54, 59-64.

[36] Ritchie KA, Macdonald EB, Hammersley R, O'Neil JM, McGowan DA, Dale IM, Wesnes K (1995) A pilot study of the effect of low level exposure to mercury on the health of dental surgeons. Occup Environ Med 52, 813-817.

[37] Ngim CH, Foo SC, Boey KW, Jeyaratnam J (1992) Chronic neurobehavioural effects of elemental mercury in dentists. Br J Ind Med 49, 782-790.

[38] Mohs RC. How Human Memory Works. https://science. howstuffworks.com/life/inside-the-mind/human-brain/hum an-memory.htm. Posted 2018. Accessed 25 May 2018.
[39] Maguire EA, Frith CD, Morris RG (1999) The functional neuroanatomy of comprehension and memory: the importance of prior knowledge. Brain 122 (Pt 10), 1839-1850.

[40] Kern JK, Geier DA, Audhya T, King PG, Sykes LK, Geier MR (2012) Evidence of parallels between mercury intoxication and the brain pathology in autism. Acta Neurobiol Exp (Wars) 72, 113-153.

[41] Geier DA, Kern JK, Homme KG, Geier MR (2017) Abnormal brain connectivity spectrum disorders following Thimerosal administration: a prospective longitudinal casecontrol assessment of medical records in the Vaccine Safety datalink. Dose Response 15, 1559325817690849.

[42] Shum J, Hermes D, Foster BL, Dastjerdi M, Rangarajan V, Winawer J, Miller KJ, Parvizi J (2013) A brain area for visual numerals. J Neurosci 33, 6709-6715.

[43] Lafer-Sousa R, Conway BR (2013) Parallel, multi-stage processing of colors, faces and shapes in macaque inferior temporal cortex. Nat Neurosci 16, 1870-1878.

[44] Tan M, Parkin JE (2000) Route of decomposition of thiomersal (thimerosal). Int J Pharm 208, 23-34.

[45] Pichichero ME, Gentile A, Giglio N, Umido V, Clarkson T, Cernichiari E, Zareba G, Gotelli C, Gotelli M, Yan L, Treanor J (2008) Mercury levels in newborns and infants after receipt of thimerosal-containing vaccines. Pediatrics 121, e208-14.

[46] Zimmermann LT, Santos DB, Naime AA, Leal RB, Dorea JG, Barbosa F Jr, Aschner M, Rocha JB, Farina M (2013) Comparative study on methyl- and ethylmercury-induced toxicity in C6 glioma cells and the potential role of LAT-1 in mediating mercurial-thiol complexes uptake. Neurotoxicology 38, 1-8.

[47] Fagan DG, Prichard JS, Clarkson TW, Greenwood MR (1977) Organ mercury levels in infants with omphaloceles treated with organic mercurial antiseptic. Arch Dis Child 52, 962-964.

[48] Burbacher TM, Shen DD, Liberato N, Grant KS, Cernichiari E, Clarkson T (2005) Comparison of blood and brain mercury levels in infant monkeys exposed to methylmercury or vaccines containing thimerosal. Environ Health Perspect 113, 1015-1021.

[49] Weil M, Bressler J, Parsons P, Bolla K, Glass T, Schwarts B (2005) Blood mercury levels and neurobehavioral function. JAMA 293, 1875-1882.

[50] Gao YX, Zhang HX, Li JG, Zhang L, Yu XW, He JL, Shang XH, Zhao YF, Wu YN (2015) The benefit risk assessment of consumption of marine species based on Benefit-Risk Analysis for Foods (BRAFO)-tiered approach. Biomed Environ Sci 28, 243-252.

[51] Fine PE, Chen RT (1992) Confounding in studies of adverse reactions to vaccines. Am J Epidemiol 136, 121-135.

[52] Nichol KL, Norden J, Mullooly J, Lask R, Fillbrandt K, Iwane M (2003) Influenza vaccination and reduction in hospitalizations for cardiac disease and stroke among the elderly. N Engl J Med 348, 1322-1332.

[53] Killin LO, Starr JM, Shiue IJ, Russ TC (2016) Environmental risk factors for dementia: a systematic review. $B M C$ Geriatr 16, 175. 